\title{
Effects of propranolol on left ventricular wall movement in patients with ischaemic heart disease
}

\author{
H VON BIBRA*, D G GIBSON, K NITYANANDAN \\ From King's College Hospital and Brompton Hospital, London
}

SUMMARY To assess the acute and chronic effects of propranolol on left ventricular wall motion, simultaneous echo-, apex-, and phonocardiograms were recorded in 10 normal subjects and in 16 patients with ischaemic heart disease, nine with co-ordinate (group A) and seven with incoordinate (group B) contraction in the control state. Records were made after $0.1 \mathrm{mg} / \mathrm{kg}$ intravenous or oral therapeutic dose for one week. In all, propranolol caused small reductions in heart rate and peak VCF. In normal subjects, intravenous and oral propranolol caused rate-related increases in the intervals $Q$ to $A 2, Q$ to minimum dimension, and $Q$ to mitral valve opening. The effects were different in patients with ischaemic heart disease. In group $\mathrm{A}$, inward wall movement ceased $80 \mathrm{~ms}$ early, and this was not attributable to a change in heart rate. Diastolic events were unaltered. In group $B$, minimum dimension already occurred early. Propranolol did not alter systolic events further, but increased delay in mitral valve opening, ' $O$ ' point, prolonged isovolumic relaxation, reduced peak rate of dimension increase, and aggravated incoordinate relaxation. It is concluded that the effects of propranolol in patients with ischaemic heart disease are modified in a manner that cannot be predicted from observations made in normal subjects. It also appears that complex drug effects can be assessed in man from the measurement of time intervals derived from multiple non-invasive techniques.

Propranolol is often used to treat patients with coronary artery disease. Though its haemodynamic effects have been studied, ${ }^{12}$ information about its action on incoordinate left ventricular wall movement is contradictory: dyskinesis having been reported as increased, ${ }^{3}$ unchanged, ${ }^{4}$ or improved ${ }^{5}$ by the drug. These discordant results might reflect the rather unsatisfactory nature of angiography as a means of studying drug action. We have therefore used echocardiography to investigate the effects of acute intravenous and chronic oral administration of propranolol in patients with coronary artery disease, with particular reference to assessing disturbances in the velocity and timing of left ventricular wall movement, rather than attempting to measure small changes in its extent.

\section{Patients}

Observations were made on 16 patients with angina pectoris (15 men and one woman, mean age $49 \pm 3$ years), in whom the diagnosis of ischaemic heart disease had been established by cardiac catheterisa-

^Present address : II Med Abt., Schwäbinger Krankenhaus, Münich. Received for publication 10 October 1979 tion and coronary arteriography at King's College Hospital. The patients all consented to take part in the study, having had full information about its nature and purpose. They were in sinus rhythm, and none had mitral or aortic regurgitation. Ten normal subjects, matched for age, sex, and oral propranolol dose were also studied, using an identical precedure.

Oral beta-blocking drugs were discontinued three days before the study. Echocardiograms with simultaneous phono- and apexcardiograms were obtained from each subject in a control resting state. In the acute study, observations were repeated 25 minutes after $0.1 \mathrm{mg} / \mathrm{kg}$ propranolol had been given intravenously. In the chronic study, the patients restarted their individual antianginal dose of oral propranolol (120 to $240 \mathrm{mg} /$ day), and were reinvestigated after one week. Arterial blood pressure was recorded by sphygmomanometer on each occasion, after the echocardiogram had been performed.

\section{Methods}

Echocardiograms were recorded with a SmithKline Ekoline 20 ultrasonoscope, using a $2 \cdot 25 \mathrm{MHz}$ 
transducer, with the patients in the left semilateral position. Echocardiograms were only accepted for analysis if they showed the time of separation of the mitral valve leaflets, and clear, continuous endocardial echoes from the posterior left ventricular wall and the left side of the septum throughout the cardiac cycle. Phonocardiograms were recorded from the position on the praecordium where splitting of the second sound was most obvious clinically, using a Leatham suction microphone and a highfrequency filter. Apexcardiograms were recorded from the position of maximum impulse. A Cambridge Scientific Instruments transducer was used with a $3 \mathrm{~cm}$ cup, a time constant of $4 \mathrm{~s}$, and a lower frequency limit of $0.05 \mathrm{~Hz}$. Echo-, apex-, and phonocardiograms were recorded simultaneously using a Cambridge photographic recorder at a paper speed of $100 \mathrm{~mm} / \mathrm{s}$ (Fig. 1).

The echocardiograms were digitised ${ }^{6}$ on a Summagraphics digitiser and processed by a Prime 300 computer system. Co-ordinates were generated from septal and posterior endocardial echoes and from the apexcardiogram, and records were calibrated by points defining $1 \mathrm{~cm}$ depth, $500 \mathrm{~ms}$ time, and two successive $Q$ waves of the cardiac cycle in question. The timing of $\mathrm{A} 2$, the onset of the first high frequency vibration of the aortic component of the second sound, and of mitral valve opening, taken as the initial separation of the mitral valve cusps at the start of filling, were also superimposed on records. At each step of the investigation, two cardiac cycles were digitised and mean values used. Continuous plots over one cardiac cycle were obtained, showing original digitised data, left ventricular cavity dimension, its rate of change both in $\mathrm{cm} / \mathrm{s}$ and normalised to refer to unit length of dimension, and the loop of dimension against apexcardiogram. ${ }^{7}$ From these plots, the following measurements were made:

(1) Time intervals: (a) Cycle length as the interval between successive $Q$ waves: the onset of the first $Q$ wave was always taken as zero time; (b) $Q$ to aortic valve closure (A2); (c) $Q$ to the onset of mitral valve opening (MVO); (d) $Q$ to the ' $O$ ' point of the apex cardiogram; (e) $Q$ to the time of minimum left ventricular dimension, the point in late systole when the first derivative of cavity dimension first changed from negative to positive; (f) $Q$ to the time of peak rate of dimension increase during diastole; $(\mathrm{g}) \mathrm{Q}$ to left ventricular dimension discontinuity, taken as

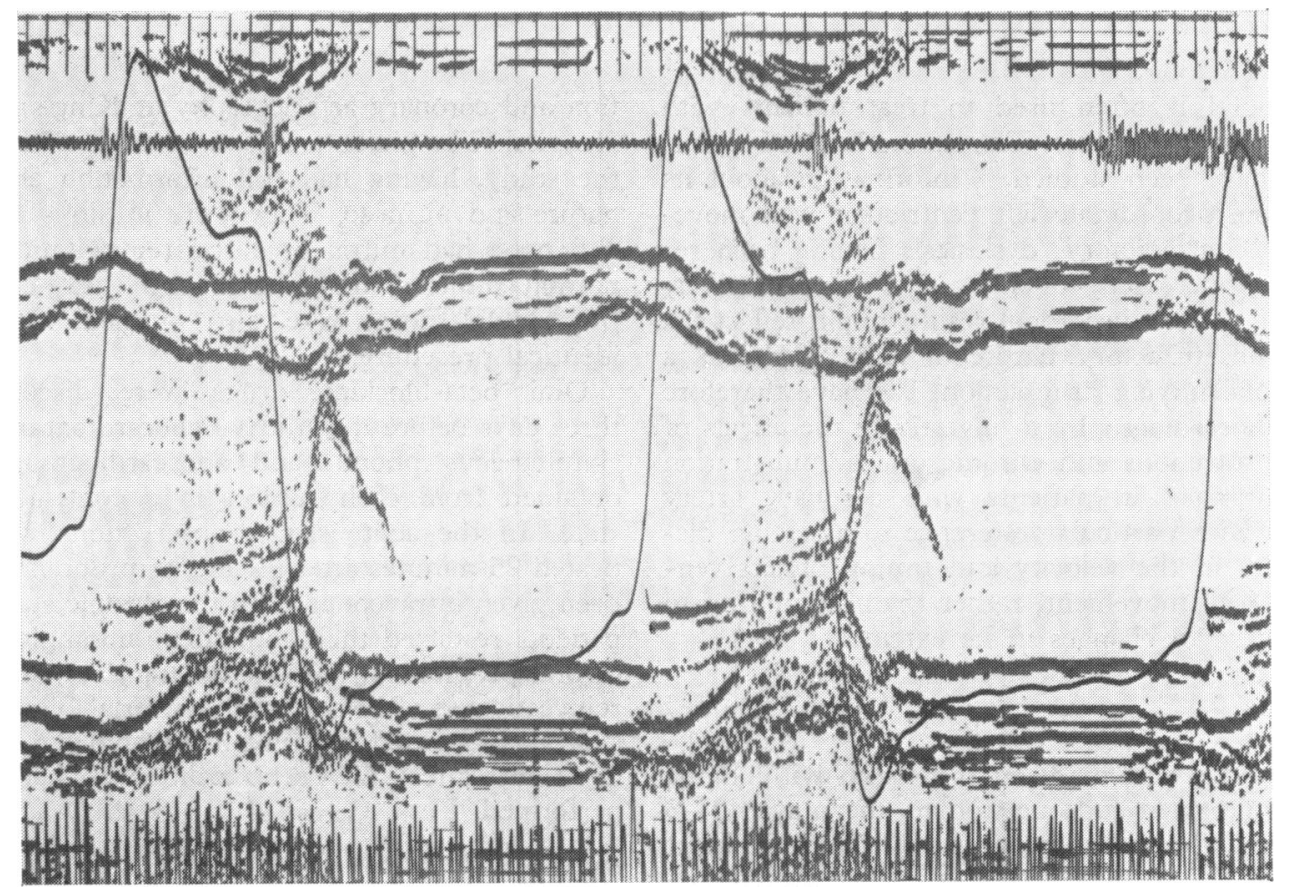

Fig. 1 Echocardiogram of left ventricular cavity from a patient with ischaemic heart disease, with simultaneous apex-, phono-, and electrocardiogram. Paper speed $100 \mathrm{~mm} / \mathrm{s}$. 
Table 1 Correlation coefficients for cycle length

\begin{tabular}{|c|c|c|c|c|c|c|c|c|c|}
\hline & \multicolumn{7}{|c|}{$Q$ wave to } & \multirow{2}{*}{$\begin{array}{l}\text { Isovolumic } \\
\text { relaxation } \\
\text { time }\end{array}$} & \multirow{2}{*}{$\begin{array}{l}\text { Aortic } \\
\text { closure to } \\
\text { 'O'point }\end{array}$} \\
\hline & $\begin{array}{l}\text { Aortic } \\
\text { closure }\end{array}$ & $\begin{array}{l}\text { Mitral } \\
\text { opening }\end{array}$ & ' $O$ ' point & $\begin{array}{l}L V \text { dis- } \\
\text { continuity }\end{array}$ & $\begin{array}{l}\text { Peak } \\
\text { filling }\end{array}$ & $\begin{array}{l}\text { Mini } \\
\text { dime } \\
A\end{array}$ & ion & & \\
\hline $\begin{array}{l}\text { Control } \\
\text { Intravenous propranolol } \\
\text { Oral propranolol }\end{array}$ & $\begin{array}{l}0.82 \\
0.79 \\
0.63\end{array}$ & $\begin{array}{l}0.75 \\
0.79 \\
0.63\end{array}$ & $\begin{array}{l}0.69 \\
0.69 \\
0.56\end{array}$ & $\begin{array}{l}0.71 \\
0.75 \\
0.48\end{array}$ & $\begin{array}{l}0.78 \\
0.77 \\
0.58\end{array}$ & $\begin{array}{l}0.75 \\
0.25 \\
0 \cdot 20\end{array}$ & $\begin{array}{l}0.79 \\
0.76 \\
0.68\end{array}$ & $\begin{array}{l}-0.29 \\
-0.13 \\
-0.34\end{array}$ & $\begin{array}{l}0.23 \\
0.22 \\
0.46\end{array}$ \\
\hline
\end{tabular}

32 degrees of freedom.

the time at which the rate of dimension increase drops abruptly to 20 per cent of less of its peak value.

(2) Changes of $L V$ dimension during following periods: (a) The time of inscription of the upstroke of the apexcardiogram, measured from the loop; (b) isovolumic relaxation, taken as the interval A2 to MVO; (c) the time of inscription of the downstroke of the apexcardiogram, measured from the loop.

(3) Normalised peak rates of dimension change:

(a) During ejection (peak VCF); (b) during diastole.

(4) Maximum and minimum left ventricular dimensions.

The patients with ischaemic heart disease were initially considered as a single group, and were then divided according to the timing of minimum cavity dimension with respect to A2. In normal subjects, A2 precedes minimum cavity dimension by $40 \pm 10$ ms (mean \pm 1 standard deviation), ${ }^{8}$ but if abnor- malities of isovolumic contraction are present then minimum cavity dimension follows $\mathrm{A} 2$ by less than $20 \mathrm{~ms}$, the 95 per cent confidence limit of normal. Group A patients (synchronous contraction) were thus taken as those with ischaemic heart disease in whom A2 preceded minimum dimension by $20 \mathrm{~ms}$ or more, and group B (asynchronous contraction) as those in whom separation was less.

Statistical significances of differences between mean values were examined by an analysis of variance. Linear regression analysis was used to measure correlation between variables. Mean values for time intervals were all expressed to the nearest $5 \mathrm{~ms}$.

These are given in detail in Tables 1 and 2 and Fig. 2 to 4 .

NORMAL SUBJECTS

In normal subjects, intravenous propranolol caused

Table 2 Effect of oral and intravenous propranolol in ischaemic heart disease

\begin{tabular}{|c|c|c|c|c|c|c|c|}
\hline \multirow[b]{3}{*}{ RR interval (ms) } & \multicolumn{3}{|c|}{ Group $A(n=9)$} & \multicolumn{3}{|c|}{ Group $B(n=7)$} & \multirow[b]{2}{*}{$S E$} \\
\hline & Control & $\begin{array}{l}\text { Propranolol } \\
\text { Intravenous }\end{array}$ & Oral & Control & $\begin{array}{l}\text { Propranolol } \\
\text { Intravenous }\end{array}$ & Oral & \\
\hline & 910 & 1045 & 1000 & 840 & 975 & 1050 & 30 \\
\hline $\begin{array}{l}\text { Q to: } \\
\text { A2 (ms) } \\
\text { Minimum dimension (ms) } \\
\text { Mitral opening (ms) } \\
\text { Peak filling (ms) } \\
\text { 'O' point (ms) } \\
\text { Discontinuity (ms) }\end{array}$ & $\begin{array}{l}385 \\
450 \\
465 \\
520 \\
525 \\
640\end{array}$ & $\begin{array}{r}415 \\
450 \\
+490 \\
535 \\
550 \\
670\end{array}$ & $\begin{array}{r}390 \\
++400 \\
470 \\
515 \\
520 \\
630\end{array}$ & $\begin{array}{l}380 \\
355^{\star \star \star} \\
445 \\
475^{\star} \\
480^{\star \star} \\
600\end{array}$ & $\begin{aligned} & 390^{\star} \\
& 370^{\star \star \star} \\
&++485 \\
& 510 \\
&++530 \\
& 630\end{aligned}$ & $\begin{array}{r}+410 \\
390 \\
++500 \\
510 \\
++545 \\
++685\end{array}$ & $\begin{array}{r}9 \\
29 \\
11 \\
24 \\
15 \\
45\end{array}$ \\
\hline $\begin{array}{l}\text { QS2 index (ms) } \\
\text { Isovolumic relaxation (ms) } \\
\text { A2 to 'O' point (ms) } \\
\text { Minimum D - A2 } \\
\text { MVO - minimum dimension (ms) }\end{array}$ & $\begin{array}{r}530 \\
80 \\
140 \\
65 \\
15\end{array}$ & $\begin{array}{r}540 \\
75 \\
130 \\
+\quad 35 \\
++45\end{array}$ & $\begin{array}{r}520 \\
80 \\
130 \\
+\quad 15 \\
++65\end{array}$ & $\begin{array}{l}540 \\
65 \\
100 \star \star \\
-25^{\star \star \star} \\
90^{\star \star \star}\end{array}$ & $\begin{array}{c}530 \\
+++95^{\star} \\
++140 \\
-15^{\star} \\
115^{\star \star \star}\end{array}$ & $\begin{array}{r}535 \\
+\quad 85 \\
+140 \\
-20 \\
110^{\star}\end{array}$ & $\begin{array}{r}8 \\
12 \\
14 \\
29 \\
29\end{array}$ \\
\hline $\begin{array}{l}\text { Dimension change (upstroke, \%) } \\
\text { Dimension change (IVR, \%) } \\
\text { Dimension change (downstroke) }\end{array}$ & $\begin{array}{l}-3 \\
-5 \\
28\end{array}$ & $\begin{array}{r}-3 \\
0 \\
33\end{array}$ & $\begin{array}{r}-8 \\
+\quad 8 \\
38\end{array}$ & $\begin{array}{l}-14^{\star \star} \\
16^{\star \star \star} \\
34\end{array}$ & $\begin{array}{l}-12^{\star} \\
28 \star \star \star \\
44\end{array}$ & $\begin{array}{l}-21 \star \star \\
23 \star \star \\
50\end{array}$ & $\begin{array}{l}6 \\
6 \\
9\end{array}$ \\
\hline $\begin{array}{l}\text { Peak VCF }\left(s^{-1}\right) \\
\text { Peak diastolic dimension increase }\left(s^{-1}\right)\end{array}$ & $\begin{array}{l}2 \cdot 5 \\
3 \cdot 6\end{array}$ & $\begin{array}{r}2 \cdot 2 \\
++\quad 3 \cdot 0\end{array}$ & $\begin{array}{l}2 \cdot 5 \\
3 \cdot 4\end{array}$ & $\begin{array}{l}2 \cdot 9 \\
3 \cdot 8\end{array}$ & $\begin{array}{l}2 \cdot 5 \\
3 \cdot 1\end{array}$ & $\begin{array}{l}2 \cdot 5 \\
3 \cdot 1\end{array}$ & $\begin{array}{l}0.53 \\
0.61\end{array}$ \\
\hline
\end{tabular}

Statistical significances: + refers to differences between control and oral or intravenous propranolol $(+, \mathrm{p}<0.05 ;++, \mathrm{p}<0.01$;

$+++, \mathrm{p}<0.001)$. $\star$ refers to differences between groups $\mathrm{A}$ and $\mathrm{B}$ for corresponding values $(\star, \mathrm{p}<0.05 ; \star \star, \mathrm{p}<0.01 ; \star \star \star, \mathrm{p}<0.001)$. MVO, mitral valve opening; discontinuity, discontinuity on first differential trace; SE, standard error. 
an increase in $R R$ interval from 845 to $1005 \mathrm{~ms}$ $(p<0.001)$. There was also prolongation of the interval from the $Q$ wave of the electrocardiogram to aortic valve closure from 370 to $400 \mathrm{~ms}(p<0.01$ ), $Q$ to minimum dimension from 420 to $455 \mathrm{~ms}$ $(\mathrm{p}<0.05)$, and $\mathrm{Q}$ to mitral valve opening from 450 to $475 \mathrm{~ms}(\mathrm{p}<0.01)$. Peak rate of dimension change during systole and diastole remained unaltered, as did the intervals aortic valve closure to minimum dimension, minimum dimension to mitral valve opening and isovolumic relaxation. The timing of the ' $O$ ' point of the apexcardiogram and of peak filling were also unaffected. Changes after oral propranolol were in a similar direction, though they were not statistically significant. Neither oral nor intravenous administration of propranolol caused any significant change in arterial pressure. However, a small reduction in peak VCF from 2.5 to $2 \cdot 1 \mathrm{~s}^{-1}$ was noted $(\mathrm{p}<0.05)$ after oral propranolol.

The increase in QA2 interval after intravenous propranolol appeared to be directly explicable on the basis of the reduction in heart rate, since there was no significant change in QS2 index. ${ }^{9}$ The effect of spontaneous variation in heart rate on the interval Q-minimum dimension was investigated in 34 ad-

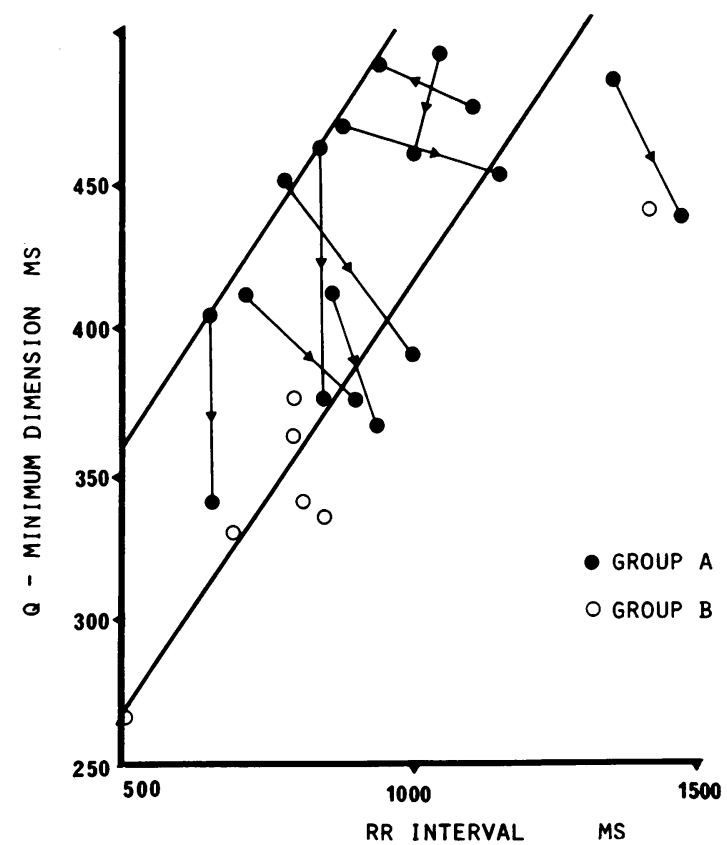

Fig. 2 Relation between changes in the interval $Q$ to minimum dimension and $R R$ interval. The limits represent two standard deviations about the regression line derived from normal subjects. Values for group $A$ patients are shown before and after oral propranolol administration, with the arrow pointing to the latter values. ditional normal subjects, and positive correlation demonstrated with $R R$ interval, the regression equation being:

$\mathrm{Q}-\min \mathrm{D}=0.29 \mathrm{RR}+170 \mathrm{~ms}, \mathrm{r}=0.86, \mathrm{p}<0.001$.

Standard error of the estimate, $23 \mathrm{~ms}$.

(Fig. 2). The increase in Q-minimum dimension interval brought about by intravenous propranolol in normal subjects was thus entirely explicable on the basis of the drop in heart rate.

\section{ISCHAEMIC HEART DISEASE}

In the patients with ischaemic heart disease, propranolol caused a significant increase in $R R$ interval of $130 \mathrm{~ms}$ after both oral and intravenous administration ( $p<0.001$ for each). This reduction in heart rate was associated with an increase in QA2 interval of $26 \mathrm{~ms}(\mathrm{p}<0.001)$, though when corrected for rate, and expressed as a QS2 index, ${ }^{9}$ it was unchanged. There were also small associated changes in the intervals $Q$ to mitral valve opening by $30 \mathrm{~ms}$ $(p<0.001$ after intravenous, and $p<0.05$ after oral propranolol), and in isovolumic relaxation time by $10 \mathrm{~ms}(\mathrm{p}<0.01)$. Maximum and minimum cavity dimensions were unchanged, but the mean reduction in dimension during systole dropped from 1.8 to $1.6 \mathrm{~cm}(\mathrm{p}<0.05)$. Peak VCF dropped from 2.7 to $2.3 \mathrm{~s}^{-1}(\mathrm{p}<0.05)$, and peak rate of dimension increase during filling from 3.7 to $3.1 \mathrm{~s}^{-1}(\mathrm{p}<0.01)$. During oral propranolol administration, there were changes in the pattern of wall movement. Incoordinate contraction became apparent, with a 14 per cent $(p<0.05)$ reduction in dimension during the time of inscription of the upstroke of the apexcardiogram (normal, up to $14 \%$ ). There was also evidence of abnormal relaxation, with an increase in dimension of 41 per cent during the downstroke of the apexcardiogram $(p<0.05$, normal up to $33 \%)$. Neither oral nor intravenous propranolol administration caused any significant change in blood pressure.

\section{Effect of heart rate}

In view of the drop in heart rate caused by propranolol administration, regression equations relating the $R R$ interval to other variables were derived, based on spontaneous variation in rate. Under control conditions, there was significant positive correlation between $R R$ interval and the intervals from $Q$ wave to minimum dimension in both group $A$ and group $B$, to A2, mitral valve opening, ' $O$ ' point, timing of peak rate dimension increase, and the end of rapid filling ( $p<0.001$ for all). The only equation to be significantly altered by propranolol administration was that between $R R$ interval and the interval $Q$ to minimum dimension in group A. After propranolol, this 
became indistinguishable from the corresponding one in group $\mathrm{B}$. The remaining relations were not altered (Table 1). Intervals within the cardiac cycle, such as isovolumic relaxation time or A2 to ' $O$ ' point, were independent of $R R$ interval.

\section{INTERACTION BETWEEN PROPRANOLOL AND}

BASAL CONTRACTION PATTERN

The initial analysis suggested that propranolol might affect the degree of incoordinate contraction, and therefore that basal contraction pattern might be a factor determining its action in individual patients. For this reason, patients with synergic (group A) and asynergic (group B) contraction in the basal state were considered separately (Table 2).

\section{Control values}

In group A (nine patients), the timing of A2 with respect to minimum dimension was normal, by definition. There was thus a slight drop in cavity dimension during isovolumic relaxation. Time relations between dimension and apexcardiogram were normal, both during isovolumic contraction and relaxation, as were peak VCF and peak rate of dimension increase during diastole. In group B ( 7 patients), defined on the basis of the abnormal timing of A2 with respect to minimum dimension, significant disturbances were also present in apexcardiogram dimension relations. There was a 14 per cent fall in dimension during the time of inscription of the upstroke, and a 34 per cent (range 8 to $71 \%$ ) during the downstroke (normal, up to $33 \%$ ). In addition, there was an abnormal dimension increase of 16 per cent (range 0 to $42 \%$ ) during isovolumic relaxation. The time interval from the $Q$ wave to minimum dimension was $95 \mathrm{~ms}$ shorter than in group $A(p<0.001)$, and that from $Q$ to ' $O$ ' point $45 \mathrm{~ms}$ less $(\mathrm{p}<0.01)$. The interval from minimum dimension to mitral valve opening was greatly prolonged to $90 \mathrm{~ms}$, compared with $15 \mathrm{~ms}$ in group $A(p<0.001)$, and that from $A 2$ to ' $O$ ' point shorter by approximately $40 \mathrm{~ms}(\mathrm{p}<0.01)$. The RR interval was slightly less in group $B$, but this difference was not statistically significant. In group B patients, therefore, there was evidence both of asynchronous contraction, and abnormalities of relaxation.

\section{Effect of propranolol in group $A$ (Fig. 2 and 3)}

Intravenous propranolol administration was associated with a significant increase in $R R$ interval from 910 to $1045 \mathrm{~ms}(\mathrm{p}<0.05)$. There were minor changes in the two intervals $Q$ to mitral valve opening and minimum dimension to A2, each significant at the 5 per cent level. Peak rate of dimension increase during diastole fell $(p<0.01)$. The effects of oral propranolol were significantly different. Though the increase in RR interval was less than after intravenous propranolol, there was a very significant drop in $Q$ to minimum dimension by $50 \mathrm{~ms}(\mathrm{p}<0.01)$, so that mitral valve opening was delayed with respect to minimum dimension by $65 \mathrm{~ms}(\mathrm{p}<0.01)$. In spite of the delay, however, left ventricular dimension increased by only 8 per cent during isovolumic relaxation, very significantly less than the corresponding figure in group $B$ patients with asynchronous contraction $(p<0.001)$. There was no significant change in left ventricular dimensions or peak VCF after either oral or intravenous propranolol.

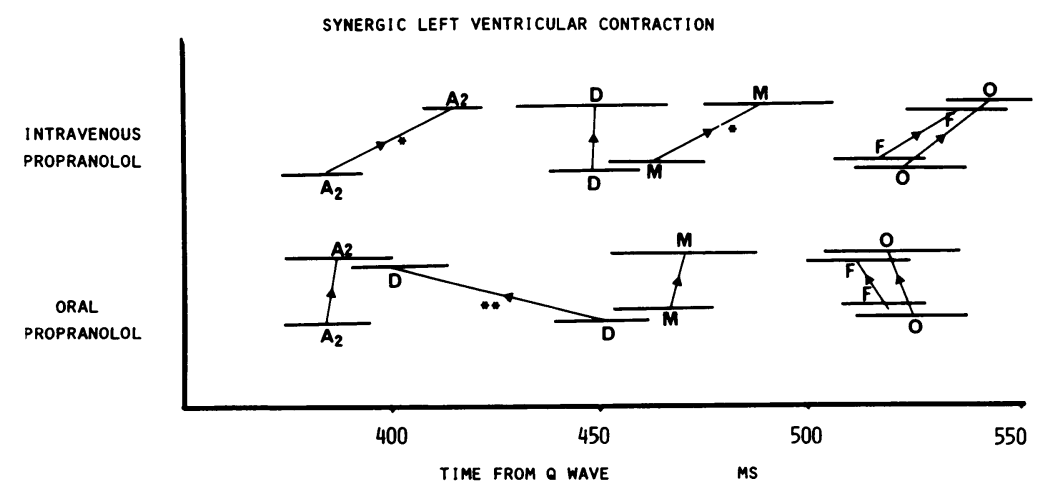

Fig. 3 Effects of intravenous or oral propranolol on diastolic events in group $A$ patients. The intervals from $Q$ to A2, minimum dimension (D), mitral valve opening ( $M$ ), the ' $O$ ' point ( $O$ ), and peak filling ( $F$ ) are shown as bars, whose length represents two standard deviations about mean values. Arrows point from control values to those after administration of the drug. Statistical significance of changes: $\star, p>0.05 ; \star \star, p>0.01$. 


\section{Effect of propranolol administration in group $B$}

The effects of propranolol administration to patients with asynchronous contraction were more complex and virtually the same whether the drug was given intravenously or orally (Fig. 4). There was significant slowing of the heart rate $(p<0.05)$. The timing of minimum dimension with respect to the $Q$ wave, already abnormally early in the control state, was unaffected, in contrast to the results after oral propranolol administration to patients in group A. However, the timing of a number of diastolic events was delayed with respect to the $Q$ wave, including mitral valve opening $(p<0.01)$, the ' $O$ ' point $(p<0.01)$, and, after oral propranolol only, the discontinuity on the dimension trace at the end of rapid filling $(p<0.01)$. Isovolumic relaxation was prolonged by 20 to $30 \mathrm{~ms}(p<0.001$ intravenous, $p<0.01$, orally), and the interval $A 2$ to ' $O$ ' point by $40 \mathrm{~ms}$ ( $p<0.01$ iv, $p<0.05$ orally). After either oral or intravenous propranolol, there was a further increase in dimension during isovolumic relaxation $(p<0.05)$, and peak rate of dimension increase was reduced $(p<0.05)$. There was no significant change in arterial pressure in either group.

\section{Discussion}

M-mode echocardiography has significant advantages for studying the action of drugs in man. Left ventricular cavity size and peak rate of dimension change can be measured with unequivocal localisation of the endocardium at a frequency response of $1000 / \mathrm{s}$. The method can also be used to detect incoordinate wall movement during isovolumic contraction and early relaxation, ${ }^{1011}$ prolongation of isolvolumic relaxation, and abnormalities of dimension change during filling with results that agree closely with cineangiography. Though the distribution of asynergic areas cannot be determined, their physiological effects are shown in a manner well suited for clinical pharmacological studies.

It has previously been shown that propranolol administration causes minor changes in left ventricular dimensions and mean VCF. ${ }^{12-14}$ These effects are small, being of the same order as the reproducibility of the method, and no longer occur when changes in heart rate or arterial pressure are prevented with atropine or phenylephrine. ${ }^{12}$ Our results are similar to these. Changes in the intervals $\mathrm{Q}$ to $\mathrm{A} 2$, minimum dimension, and mitral valve opening in normal subjects were all explicable on the basis of heart rate. The results in patients with coronary artery disease showed wider scatter, but there were significant reductions in peak VCF and the rate of dimension increase during diastole, and also in the extent of overall dimension shortening during systole.

When the patients were divided into two groups dependent on basal contraction pattern, however, well-defined effects of propranolol became apparent. Though a single criterion, the timing of A2 with respect ot minimum dimension, was used to define asynergic contraction, patients identified in this way differed from the remainder in showing other evidence of incoordinate contraction, including abnormal dimension changes during isovolumic contraction and early relaxation as well as delay in mitral valve opening.

In patients with a synergic contraction pattern in the control state, intravenous propranolol had identical effects to those seen in the normal group. With chronic oral administration, however, the normal reduction in left ventricular dimension during isovolumic relaxation did not take place. Minimum dimension therefore occurred early with respect to the $Q$ wave, the reverse of what would be predicted from the drop in heart rate (Fig. 2). Since the duration of electromechanical systole was unaltered, A2 came to be synchronous with minimum dimension. Isovolumic relaxation time re-
Fig. 4 Effects of intravenous or oral propranolol on diastolic events in group $B$ patients. Layout as in Fig. 3.
ASYNERGIC LEFT VENTRICULAR CONTRACTION

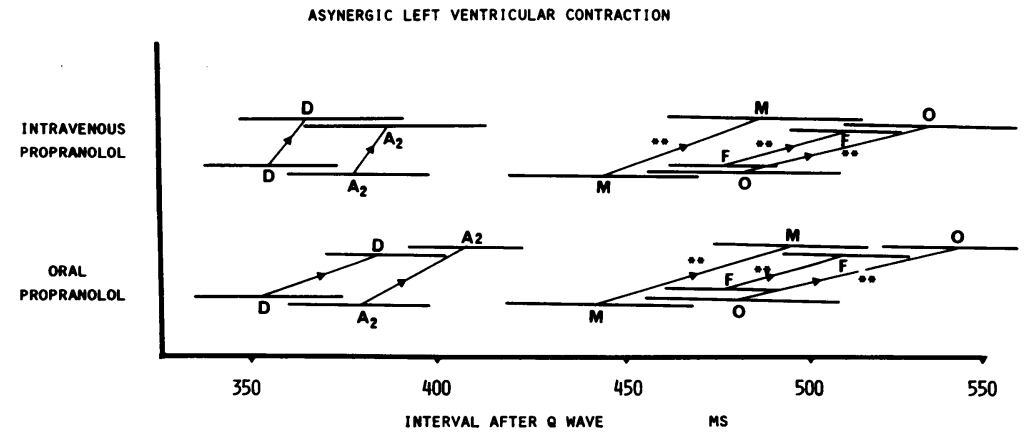


mained constant, so that mitral valve opening was now delayed with respect to minimum dimension rather than being synchronous with it. In spite of this, dimension increased by only 8 per cent during isovolumic relaxation, in contrast to the 23 per cent seen in patients in the asynergic group during the same period. Neither oral nor intravenous propranolol caused incoordinate contraction to appear or the timing of diastolic events to be altered. The reason for the difference between oral and intravenous propranolol on the timing of minimum dimension was not clear, though it is reminiscent of similar differences in action between acute intravenous and chronic oral propranolol administration on peripheral resistance in hypertensive patients. ${ }^{15} 16$

The effects of propranolol in patients with evidence of asynergic contraction under basal conditions were quite different. Q-A2 interval was normal for heart rate, and remained so. In the control state, $Q$ to minimum dimension was already approximately $80 \mathrm{~ms}$ shorter than that predicted from heart rate in normal subjects, and was unaffected by propranolol. Instead, a series of diastolic abnormalities appeared, which included further delay in mitral valve opening, prolongation of isovolumic relaxation, delay in the timing of the ' $O$ ' point with respect to $A 2$, and a reduction in the peak rate of dimension increase during diastole, whose timing now came to coincide with the onset of mitral valve opening. At the same time, relaxation became more incoordinate, with a further increase in dimension during the period before mitral valve opening and the ' $O$ ' point of the apexcardiogram. It is possible that these contrasting effects of propranolol in our two groups of patients might explain apparent contradictions in previous descriptions of its action on regional left ventricular wall movement in patients with ischaemic heart disease.

Diastolic abnormalities induced by propranolol have received little attention, and their genesis is not entirely clear. Two were seen in the present study. We cannot explain the reduction in the time interval from $Q$ wave to minimum dimension. It was the reverse of that predicted from the fall in heart rate, and could not be ascribed to any change in arterial pressure. Its basis was loss of the normal reduction in dimension during isovolumic relaxation, which itself is brought about by an increase in posterior wall thickness. ${ }^{17}$ In our patients, therefore, thinning began prematurely. This occurred under two clearly defined sets of conditions; either as a manifestation of asynergic contraction in the control state or as an effect of propranolol administration to patients with ischaemic heart disease in whom contraction was initially synergic. Pre-existing left ventricular disease was a necessary condition for its appearance, since it was not seen after propranolol administration to normal subjects. It was not simply caused by beta-blockade, because it did not occur after intravenous propranolol in spite of a significant fall in heart rate. It was not the result of a negative inotropic stimulus modifying the relation between end-systolic pressure and volume, ${ }^{18}$ because the dominant abnormality was one of dimension and wall thickness change during isovolumic relaxation rather than ejection. Finally, the two mechanisms causing shortening of the interval Q-minimum dimension were not additive, since propranolol had no further effect in patients with asynergic contraction in whom it was already short in the control state. This suggests that maximum possible shortening has occurred when A2 is synchronous with minimum dimension. The mechanism underlying the normal dimension reduction during isovolumic relaxation, in being sensitive to this effect of left ventricular disease or propranolol, can thus be distinguished from that operating during ejection, which is not.

The second diastolic abnormality induced by propranolol was to increase the delay in mitral valve opening and to aggravate abnormalities of wall movement during filling in patients with asynergic contraction. This is unlikely to have been a direct effect of the drug on relaxation, since it did not appear in normal subjects or in patients with synergic contraction. It has previously been shown that in patients with coronary artery disease, delayed mitral valve opening and incoordinate wall movement during filling are frequently caused by asynchronous termination of systole in different regions of the cavity, rather than being a primary disturbance of relaxation. ${ }^{19}$ This causes A2 to be delayed with respect to minimum dimension, ${ }^{8}$ the criterion we used to define patients with asynchronous contraction. Propranolol could thus aggravate diastolic abnormalities simply by exacerbating differences in timing between normal and abnormal regions of the ventricle. Its lack of effect on wall movement during isovolumic contraction in all our patients as well as its failure to induce relaxation abnormalities in those in whom contraction is initially synergic suggest that propranolol aggravates incoordination by increasing the effects of abnormalities already present rather than by inducing new ones.

The effects of propranolol on left ventricular wall movement in patients with coronary artery disease are thus complex. There was no demonstrable increase in end-diastolic dimension, probably because the patients were studied supine, with the 
pericardium preventing any significant increase in cavity size. There was a uniform reduction in heart rate and a slight fall in peak VCF, both compatible with blockade of sympathetic activity present under control conditions in these patients, many of whom had severe left ventricular disease. The main effects, however, were to be seen during the early phases of relaxation, and were determined by the state of left ventricular function in the control state. It follows that the effect of propranolol in patients in whom it is to be used therapeutically cannot be predicted from the results of studies in normal subjects. It also rppears that incoordinate left ventricular contraction of the type seen in ischaemic heart disease can be modified pharmacologically. Finally, and in more general terms, the investigation of drug action by echocardiography can be extended from simple measurements of small dimensional changes to the determination of the timing and relation of wall movement to a series of well-defined events throughout the cardiac cycle, identified with additional information from the phono- and apexcardiogram. Such methods may be regarded as an extension of those previously established using the systolic time intervals, and, as with the latter, it is possible to make appropriate allowance for the effects of changes in heart rate. A significant improvement in specificity is obtained, however, when information from the digitised $\mathrm{M}$-mode echocardiogram is included, so that it becomes possible to study diastolic as well as systolic events, and to undertake a complex analysis of left ventricular wall movement in a manner not easily accessible even to standard invasive techniques.

The authors thank Dr S Oram for co-operation, and Deutsche Forschungsgemeinschaft for support.

\section{References}

1Sowton E, Hamer J. Hemodynamic changes after beta adrenergic blockade. An f Cardiol 1966; 18: 317-20.

${ }^{2}$ Parker SO, West RO, Di Giorgi S. Hemodynamic effects of propranolol in coronary artery disease. $\mathrm{Am}$ f Cardiol 1968; 21: 11-19.

${ }^{3}$ Helfant RH, Herman MV, Gorlin R. Abnormalities of left ventricular contraction induced by beta adrenergic blockade. Circulation 1971; 43: 641-7.

${ }_{4}^{4}$ Shubrooks SJ Jr, Zir CM, Dinsmore RE, Harthorne JW. Left ventricular wall motion response to intravenous propranolol. Circulation 1975; 52: 124-9.
${ }^{5}$ Coltart DJ, Alderman EL, Robison SC, Harrison DC. Effect of propranolol on left ventricular function, segmental wall motion and diastolic pressure-volume relation in man. Br Heart f 1975; 37: 357-64.

${ }^{6}$ Gibson D, Brown D. Measurement of instantaneous left ventricular dimension and filling rate in man, using echocardiography. Br Heart $\mathcal{F}$ 1973; 35: 1141-9. ${ }^{7}$ Venco A, Gibson DG, Brown DJ. Relation between apexcardiogram and changes in left ventricular pressure and dimension. Br Heart $\mathcal{F} 1977$; 39: 117-25.

${ }^{8} \mathrm{Chen}$ W, Gibson DG. Relation of isovolumic relaxation to left ventricular wall movement in man. Br Heart $\mathcal{F}$ 1979; 42: 51-6.

${ }^{9}$ Weissler AM, Harris WS, Schoenfeld CD. Systolic time intervals in heart failure in man. Circulation 1968; 37: 149-59.

${ }^{10}$ Upton MT, Gibson DG. The study of left ventricular function from digitized echocardiograms. Prog Cardiovasc Dis 1978; 20: 359-84.

${ }^{11}$ Doran JH, Traill TA, Brown DJ, Gibson DG. Detection of abnormal left ventricular wall movement during isovolumic contraction and early relaxation: comparison of echo- and angiocardiography. $\mathrm{Br}$ Heart f 1978; 40: 367-71.

${ }^{12}$ Crawford MH, O'Rourke RA, Graca G, Karliner JS. Oral propranolol: effects on left ventricular function in normal subjects (abstract). Circulation 1975; 51 and 52, suppl. II: 172.

${ }^{13}$ Frishman W, Smithen C, Befler C, Kligfield P, Killip T. Noninvasive assessment of clinical response to oral propranolol. Am f Cardiol 1975; 35: 635-44.

${ }^{14}$ Winkle RA, Goodman DJ, Popp RL. Echocardiographic evaluation of propranolol therapy for mitral valve prolapse. $B r$ Heart $\mathcal{F} 1976$; 38: 129-34.

${ }^{15}$ Frohlich ED, Tarazi RC, Dustan HP. The paradox of beta adrenergic blockade in hypertension. Circulation 1968; 37: 417-22.

${ }^{16}$ Ulrych $M$, Frohlich ED, Dustan HP, Page IH. Immediate hemodynamic effects of beta-adrenergic blockade in normotensive man. Circulation 1968; 37: 411-6.

${ }^{17}$ Traill TA, Gibson DG, Brown DJ. Study of left ventricular wall thickness and dimension, using echocardiography. Br Heart $\mathcal{f}$ 1978; 40: 162-9.

${ }^{18}$ Grossman W, Braunwald E, Mann T, McLaurin LP, Green LH. Contractile state of the left ventricle in man as evaluated from end-systolic pressure-volume measurements. Circulation 1977; 56: 845-52.

${ }^{19}$ Gibson DG, Doran JH, Traill TA, Brown DJ. Abnormal left ventricular wall movement during early systole in patients with angina pectoris. $B r$ Heart $\mathcal{F}$ 1978; 40: 758-66.

Requests for reprints to Dr D G Gibson, Cardiac Department, Brompton Hospital, Fulham Road, London SW3 6HP. 